\title{
Garlic oil suppresses high-fat diet induced obesity in rats through the upregulation of UCP-1 and the enhancement of energy expenditure
}

\author{
YUKI KAGAWA ${ }^{1}$, YORI OZAKI-MASUZAWA ${ }^{2}$, TAKASHI HOSONO ${ }^{1,2}$ and TAIICHIRO SEKI ${ }^{1,2}$ \\ ${ }^{1}$ Department of Applied Life Science, Nihon University Graduate School of Bioresource Sciences; ${ }^{2}$ Department of \\ Chemistry and Life Science, College of Bioresource Sciences, Nihon University, Fujisawa, Kanagawa 252-0880, Japan
}

Received August 19, 2019; Accepted September 27, 2019

DOI: $10.3892 /$ etm.2019.8386

\begin{abstract}
Garlic (Allium sativum L.) has long been used as a medicinal food. Indeed, garlic and its constituents have been shown to possess potent regulatory activities in bodily functions, including blood coagulation, lipid metabolism, immunity and xenobiotic metabolism. In this study, we aimed to examine the anti-obesity effects of garlic oil and to elucidate the possible underlying mechanisms. For this purpose, garlic oil (GO; $80 \mathrm{mg} / \mathrm{kg}$ body weight, p.o.) or corn oil alone as a vehicle-control were administered to male Sprague-Dawley rats every other day for 10 weeks. The results revealed that GO administration significantly reduced body weight gain and white adipose tissue (WAT) mass, which had been increased by feeding on the AIN-76-based high-fat diet (60\% kcal fat). Expired gas analysis was performed at 9 weeks following the GO administration to calculate fuel oxidation. GO administration enhanced $\mathrm{O}_{2}$ consumption during the dark period (at night) and increased energy expenditure through fat oxidation during the light period (daytime); however, carbohydrate oxidation remained unaltered. Western blot analysis revealed that GO administration increased UCP1 protein expression in brown adipose tissue (BAT). On the whole, the findings of this study indicated that GO suppressed body weight gain and WAT mass in the rat model of high-fat diet-induced obesity by
\end{abstract}

Correspondence to: Dr Taiichiro Seki, Department of Applied Life Science, Nihon University Graduate School of Bioresource Sciences, 1866 Kameino, Fujisawa, Kanagawa 252-0880, Japan E-mail: seki.taiichirou@nihon-u.ac.jp

Abbreviations: BAT, brown adipose tissue; C/EBP, CCAAT/ enhancer-binding protein; COX-4, cytochrome $c$ oxidase subunit 4; DATS, diallyl trisulfide; DADS, diallyl disulfide; DAS, diallyl sulfide; EE, energy expenditure; GO, garlic oil; MATS, methyl allyl trisulfide; PPAR, peroxisome proliferator-activated receptor; TRPA, transient receptor potential cation channel, subfamily A, member 1; UCP, uncoupling protein; WAT, white adipose tissue; ZT, Zeitgeber time

Key words: garlic, obesity, energy expenditure, fat oxidation, UCP1 increasing UCP1 expression and by enhancing fat oxidation and energy expenditure.

\section{Introduction}

Obesity is a global threat to the health of individuals. Approximately 1.9 billion adults are overweight and 600 million are obese worldwide (1). Due to the fact that the mechanisms of pathologies underlining obesity differ among individuals, the discovery of novel compounds from diverse sources and novel developments for new categories of medications are urgently required for the prevention and treatment of obesity and its related metabolic disorders, including diabetes (2). Thus far, lifestyle intervention has been a first choice for the treatment of obesity; however, the lifestyle interventions are limited by low efficacy and high drop-out rates.

Obesity is characterized by the excessive accumulation of triglycerides in adipose tissues, including in visceral and subcutaneous adipose tissues (3). Adipose tissue also acts as an endocrine organ, which secretes a variety of cytokines, termed adipocytokines. Adipocytokines are involved in the pathophysiology of obesity, such as insulin resistance and metabolic syndrome. Obesity is an independent risk factor for the promotion of arteriosclerosis followed by the onset of thrombotic diseases, such as myocardial infarction (4).

Adipose tissue can be categorized into white adipose tissue (WAT) and brown adipose tissue (BAT) according to their phenotype. The major cell type present in BAT is brown adipocytes. Brown adipocytes contain small lipid droplets and have a high density of mitochondria, which is a causative of the brown appearance. On the other hand, WAT contains white adipocytes with unilocular lipid droplets. BAT is involved in thermogenesis and energy expenditure via uncoupling protein-1 (UCP1) located in the mitochondrion, which uncouples oxidative phosphorylation from adenosine triphosphate (ATP) production (5). WAT is involved in fat storage and the production of adipocytokines in an endocrine manner. In response to various stimuli, UCP1-expressing multilocular adipocytes develop into WAT (6).

Garlic (Allium sativum L.) has long been used as a medicinal food worldwide, as well as a spice (7). It has been reported that garlic has various biological functions through 
which it procures medicinal benefits to the human body, such as antibiotic (8-11), antithrombotic (12), anticancer (13-16), antioxidant (17), anti-hypertensive (18) and antilipidemic (19) effects. These effects are attributed to organosulfur compounds derived from garlic (7). Garlic oil (GO) is produced by the steam distillation of raw garlic homogenate; normally, 0.2-0.6 ml of garlic oil is obtained from $100 \mathrm{~g}$ of garlic homogenate. The major constituents of GO are allyl sulfides, including diallyl trisulfide (DATS), diallyl disulfide (DADS), diallyl sulfide (DAS) and methyl allyl trisulfide (MATS) (20). These sulfide compounds are considered to be responsible for the potent physiological functions of garlic.

In this study, we aimed to investigate the anti-obesity effects of GO in a rat model of high-fat diet-induced obesity. In addition, we aimed to elucidate the underlying mechanisms of the anti-obesity effects of GO in terms of energy metabolism.

\section{Materials and methods}

Rats and diets. All experiments in this study were performed in accordance with the National Institutes of Health Guide for the Care and Use of Laboratory Animals, and were approved by the Nihon University Animal Care and Use Committee (approval no. AP11B008). The animals used in this study were 5-week-old male Sprague-Dawley (SD) rats (Japan SLC). Ten of the SD rats were introduced and housed individually in a stainless-steel wire-bottomed cage in a temperature-controlled room $\left(22-23^{\circ} \mathrm{C}\right)$ with a 12 -h photoperiod. The rats were provided with a high-fat diet (60\% of total energy as fat) prepared based on the composition of AIN-76 (21) and were provided with water ad libitum. The diet contained 5\% (wt:wt) corn oil, 31.9\% (wt:wt) lard, 28\% (wt:wt) casein, $0.4 \%$ (wt:wt) D,L-methionine, 15\% (wt:wt) corn starch, $10 \%$ (wt:wt) sucrose, $1 \%$ (wt:wt) vitamins, 3.5\% minerals $0.2 \%$ (wt:wt) choline bitartrate and 5\% (wt:wt) cellulose. Following 2 weeks of acclimatization, the rats were divided into 2 groups with matched body weight; i.e., i) The vehicle-administered control group (Vehicle group, 5 rats); and ii) the GO-administered group (GO group, 5 rats). GO (Riken Chemical Ind. Co., Ltd.; $80 \mathrm{mg} / \mathrm{kg}$ body weight) was administered per os (p.o.) with corn oil ( $2 \mathrm{ml} / \mathrm{kg}$ body weight; Wako Pure Chemical Industries, Ltd) every other day for 10 weeks. The same amount of corn oil without GO was administered to the Vehicle group. The dose of GO was decided upon according to a previous study (17); the effective dose of DATS (500 $\mu \mathrm{mol} / \mathrm{kg}$ body weight) in the study was considered to determine the dose of GO.

Expired gas analysis. To clarify the mechanisms responsible for the anti-obesity effects of garlic, we performed expired gas analysis by measuring the oxygen consumption $\left(\mathrm{VO}_{2}\right)$ and validation of carbon dioxide production $\left(\mathrm{VCO}_{2}\right)$ at 9 weeks following GO administration. The respiratory metabolism was analyzed by the use of Oxymax equal flowTM (Columbus Instruments). The rats were placed in the instrument chamber for $24 \mathrm{~h}$ prior to the expired gas analysis for the purpose of acclimatization, and the analyses were then performed every $10 \mathrm{~min}$. The respiratory exchange ratio (RER), energy expenditure (EE) and fuel oxidations were calculated using the following equations as previously described $(22,23)$ : $\mathrm{RER}=\mathrm{VCO}_{2} / \mathrm{VO}_{2} ; \mathrm{EE}(\mathrm{kcal} / \mathrm{h})=\left(3.815+1.232 \times \mathrm{VO}_{2}\right) \times \mathrm{RER} ;$ fat oxidation $(\mathrm{kcal} / \mathrm{h})=(1-\mathrm{RER}) / 0.3 \mathrm{x} \mathrm{EE}$; glucose oxidation $(\mathrm{kcal} / \mathrm{h})=\mathrm{EE}-$ fat oxidation .

Western blot analysis. Following 10 weeks of GO administration, the rats were fasted for $4 \mathrm{~h}$ and then sacrificed by $\mathrm{CO}_{2}$ euthanasia (fill rate of approximately $20 \%$ of the chamber volume per minute with $\mathrm{CO}_{2}$ ). Following the verification of the death of rats by observations for lack of respiration, absence of heartbeat and faded eye color, the epididymal, perirenal, mesenteric, subcutaneous WAT and interscapular BAT were collected and then frozen immediately by flashing the samples with liquid nitrogen. These tissue samples were stored at $-80^{\circ} \mathrm{C}$ until analysis. Western blot analysis was then performed as previously described (24). Briefly, the mitochondrial fraction prepared from BAT was dissolved in $0.5 \%$ protease inhibitor cocktail (Sigma) containing STE buffer $(0.25 \mathrm{M}$ sucrose, $5 \mathrm{mM}$ Tris-HCl, $2 \mathrm{mM}$ EGTA, $\mathrm{pH}$ 7.4) and the protein concentration was measured using the Pierce ${ }^{\mathrm{TM}}$ BCA Protein Assay kit (Thermo Fisher Scientific). The protein samples ( $1 \mu \mathrm{g} /$ lane) were subjected to SDS-PAGE (10\% gel), and the proteins migrated were electrically transferred to a polyvinylidene fluoride (PVDF) microporous membrane (Millipore Corp.). The membrane was incubated with $10 \%$ skimmed milk (Yukijirushi Milk Products Co., Ltd.) in 0.1\% Tween-20, $100 \mathrm{mM} \mathrm{NaCl}, 10 \mathrm{mM}$ Tris- $\mathrm{HCl}$ ( $\mathrm{pH} 7.4)$, at room temperature for $10 \mathrm{~min}$ followed by the reaction with anti-UCP1 rabbit antibody (1:5,000; cat. no. ab10983, poly clonal, Abcam) and anti-cytochrome $c$ oxidase subunit 4 (COX-4) mouse monoclonal antibody (1:5,000; sc-376731, Santa Cruz Biotechnology, Inc.) at $4^{\circ} \mathrm{C}$ for $18 \mathrm{~h}$. Following incubation, peroxidase-AffiniPure goat anti-rabbit IgG (HL) (1:20,000; cat. no. 111-035-003, Jackson ImmunoResearch Laboratories, Inc.) or goat anti-mouse IgG (H+L) HRP conjugate (1:20,000; cat. no. 115-035-003, Jackson ImmunoResearch Laboratories, Inc.) were added and allowed to stand for $30 \mathrm{~min}$ at room temperature. The antigenic proteins on the membrane were visualized by chemiluminescence using a Lumi-LightPLUS Western blotting kit (Roche Diagnostics), and the images were analyzed using an Image Analyzer LAS-4000 (Fujifilm).

Statistical analysis. Each result is expressed as the mean \pm SE and was analyzed using Prism 6 software (GraphPad Software). The statistical comparison between two groups was analyzed using a Student's t-test. One-way analysis of variance followed by Tukey's post hoc test was used to analyze differences among multiple groups. All experiments were performed duplicate. $\mathrm{P}<0.05$ was considered to indicate a statistically significant difference.

\section{Results}

Body weight gain, food intake, energy efficiency, fat accumulation. The body weights gain of the rats administered GO for 10 weeks were significantly lower than those of the control rats administered corn oil (Vehicle group) (Fig. 1A). On the other hand, there were no marked differences in food intake between the Vehicle and GO groups (Fig. 1B). Food efficiency (body weight gain/food intake) was also significantly lower in the GO group than in the Vehicle group (Fig. 1C). In good 

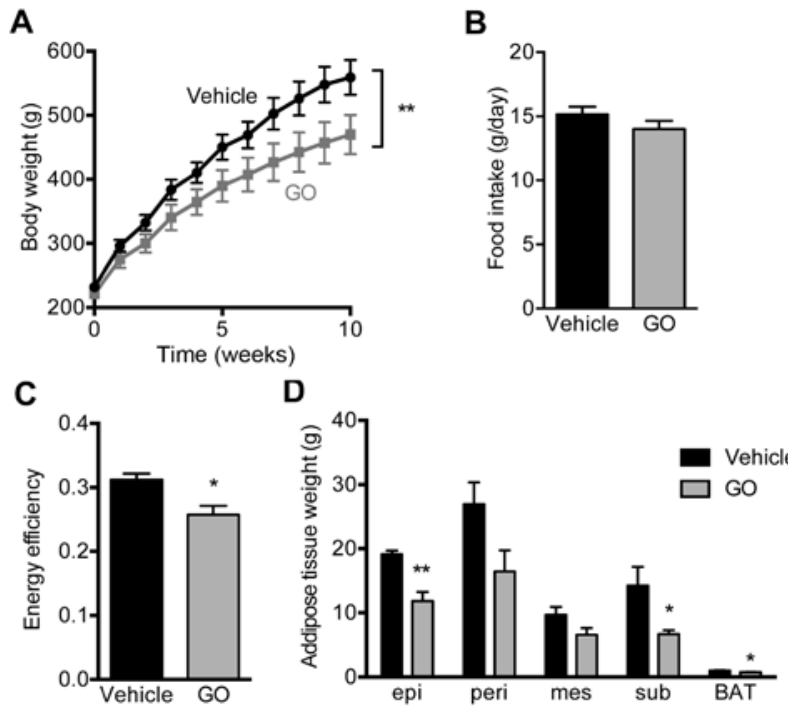

Figure 1. Effects of garlic oil administration on (A) body weight gain (B) food intake, (C) energy efficiency, and (D) adipose tissue weight. Each value represents the mean $\pm \mathrm{SE}$ of 5 different rats. The statistical comparison between the vehicle control (Vehicle) and garlic oil (GO)-administered groups was carried out using a Student's t-test. epi, epididymal adipose tissue; peri, perirenal adipose tissue; mes, mesenteric adipose tissue; sub, subcutaneous adipose tissue; BAT, interscapular brown adipose tissue.
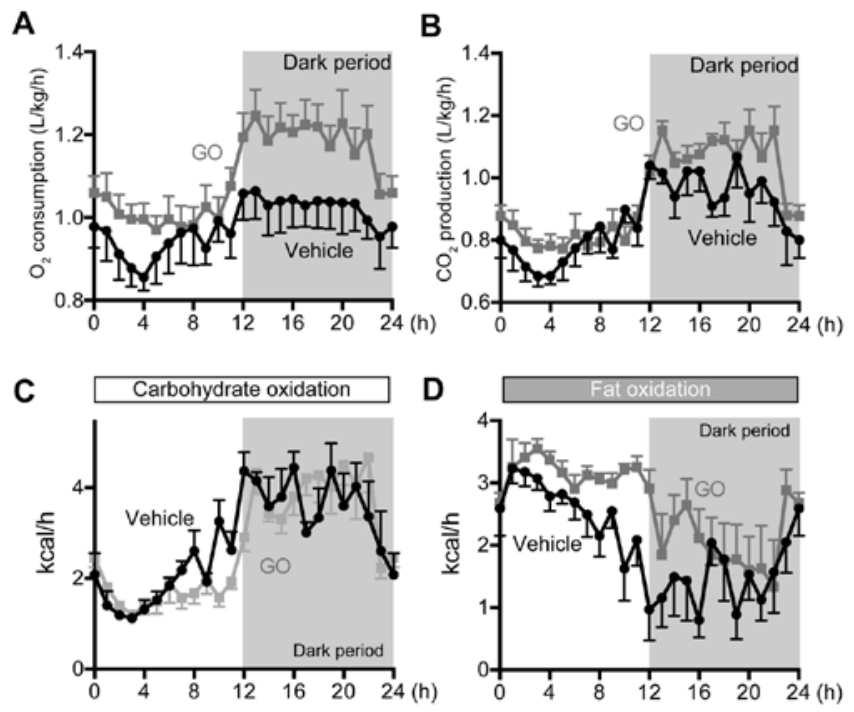

Figure 2. Circadian changes in oxygen consumption, $\mathrm{CO}_{2}$ production, carbohydrate oxidation and fat oxidation by the rats administered garlic oil. The $\mathrm{x}$-axes indicate the time as Zeitgeber time (h). The time course of changes in (A) oxygen consumption, (B) $\mathrm{CO}_{2}$ production, (C) carbohydrate oxidation and (D) fat oxidation. Values are the mean \pm SE of 5 different rats. GO, garlic oil-administered rats; Vehicle, corn oil-administered control rats; h, hours.

accordance with the suppression of body weight gain, total WAT weight including epididymal adipose tissue, perirenal adipose tissue, mesenteric adipose tissue, and subcutaneous adipose tissue against body weight (WAT \%) in the GO group $(8.8 \pm 0.8)$ was significantly lower than that in the Vehicle group (12.3 $\pm 0.8 ; \mathrm{P}<0.05)$. Among the WATs, epididymal and subcutaneous adipose tissues were significantly decreased; however, perirenal $(\mathrm{P}=0.07)$ and mesenteric $(\mathrm{P}=0.28)$ adipose tissues tended to decrease by GO administration, although not

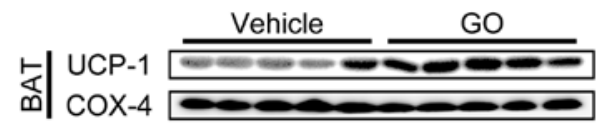

Figure 3. Western blot analyses of UCP1 expression in BAT of rats administered garlic oil. Each lane in the group represents the individual rat, n=5. UCP1, uncoupling protein 1; BAT, brown adipose tissue; COX-4, cytochrome $c$ oxidase subunit 4 .

significantly. The weight of BAT was also influenced by GO administration (Fig. 1D).

Expired gas analyses. Expired gas analyses were performed at 9 weeks following GO administration. GO was precisely administered at Zeitgeber time (ZT) 0 (8:00 a.m.; Fig. 2). Oxygen consumption in both groups was markedly higher during the dark period (active time for rats) than during the light period (inactive, sleeping time for rats), and it increased by $\mathrm{GO}$ administration in comparison with the Vehicle group during the dark period (Fig. 2A). Similarly, $\mathrm{CO}_{2}$ production was markedly higher in the GO group than the Vehicle group during the dark period (Fig. 2B). As regards fuel oxidation, no significant differences were observed in carbohydrate oxidation between the GO and Vehicle groups (Fig. 2C). On the other hand, fat oxidation was high during the light period than the dark period in both the GO and Vehicle groups (Fig. 2D). In contrast to carbohydrate oxidation, fat oxidation was higher in the GO group than the Vehicle group (Fig. 2C and D).

UCP-1 protein expression. UCP-1 protein expression in BAT was measured by western blot analysis using the mitochondrial fraction prepared from BAT (Fig. 3). COX-4 was employed as the loading control in this analysis. UCP-1 protein expression in BAT was markedly increased in the GO group in comparison with the Vehicle group (Fig. 3).

\section{Discussion}

Garlic has been known to possess a variety of compounds which affects our body functions. In this study, we demonstrated the anti-obesity effects of GO in a rat model of high-fat diet-induced obesity. The body weight gain and the total mass of WAT were significantly reduced in the rats administered GO in comparison with the vehicle-administered control rats. On the other hand, no differences in energy intake were observed between the GO group and the Vehicle group, indicating that the anti-obesity effects were not due to the anorectic effect induced by $\mathrm{GO}$ administration. It has been reported that garlic exerts anti-obesity effects in animal models of obesity by using garlic powder (25) and garlic extracts $(26,27)$. In these studies, water-soluble compounds, such as allicin, phenolic compounds, or fiber compositions were suggested to be responsible for the anti-obesity effects (25-27). In this study, we focused on the effects of GO, which contains a variety of oil soluble organosulfur compounds. The major components of the GO used in this study were as follows (20): DATS (31.5\%), DADS (21.5\%), DAS (16.3\%) and MATS (7.8\%). These sulfides, particularly DATS, are considered to be responsible for the physiological functions of garlic $(7,13-15,16)$. 
In relation to the anti-obesity effects of garlic, DATS has been reported to inhibit adipogenesis in vitro. DATS has been shown to downregulate CCAAT/enhancer-binding protein $(\mathrm{C} / \mathrm{EBP}) \alpha$ and $\beta$ and peroxisome proliferator-activated receptor (PPAR) $\gamma$ leading to a decrease in fatty acid synthase and lipid accumulation in 3T3-L1 adipocytes (28). Another lipophilic component, 1,2-vinyldithiin, which is mainly found in the oily macerate of crushed garlic, leading to the degradation of allicin, has also been shown to inhibit the differentiation and inflammation of human preadipocytes by decreasing $\mathrm{C} / \mathrm{EBP} \alpha$, PPAR $\gamma$, interleukin- 6 and monocyte chemoattractant protein-1 expression (29). These inhibitory effects of garlic compounds on adipocyte differentiation and lipid accumulation, as well as on adipocytokine production may also be responsible for the anti-obesity effects of garlic.

The energy efficiency of the rats administered GO in this study was significantly decreased in comparison with the vehicle-administered control rats (Fig. 1C). Thus, we performed an expired gas analyses to measure energy expenditure in the $\mathrm{GO}$-administered rats. In the $\mathrm{GO}$-administered rats, an overall higher $\mathrm{O}_{2}$ consumption was observed compared with the vehicle-administered control rats (Fig. $2 \mathrm{~A}) ; \mathrm{O}_{2}$ consumption by the rats administered GO, particularly during the dark period, was significantly higher than that by the vehicle-administered rats. This increase in $\mathrm{O}_{2}$ consumption seems more obvious, as it was measured at 9 weeks following GO administration with significantly different body weights observed between the GO-administered group and the vehicle-administered group (Fig. 1A). We further calculated the carbohydrate and fat oxidation rate of these rats, according to the method described in the study by Lusk (22). No differences were observed in carbohydrate oxidation between the GO-administered rats and the vehicle-administered control rats (Fig. 2C); however, fat oxidation was higher in the GO-administered rats than that in the control rats (Fig. 2D). These data indicate that GO enhances $\mathrm{O}_{2}$ consumption during the dark period and stimulates fat oxidation rather than carbohydrate oxidation during the light period.

UCP1 plays important roles in non-shivering heat production by BAT. Thermogenesis in BAT is activated by the sympathetic nerve system through norepinephrine, thyroid hormone and the signals produced by $\beta$-adrenergic receptor (30). UCP1 in BAT is an important target for the development of anti-obesity nutraceuticals. The UCP1 expression in BAT was potently upregulated by GO administration. We previously reported that DAS, DADS, and DATS were agonists of both transient receptor potential cation channel, subfamily $\mathrm{A}$, member 1 (TRPA1) and transient receptor potential cation channel subfamily V member 1 (TRPV1) (31). Surprisingly, DATS $\left(\mathrm{EC}_{50}, 0.49 \mu \mathrm{mol} / \mathrm{l}\right)$ was shown to be a much more potent agonist than allyl isothiocyanate $\left(\mathrm{EC}_{50}, 1.47 \mu \mathrm{mol} / \mathrm{l}\right)$, which is a representative agonist of TRPA1 in the assay system, which employs TRPA1-overexpressing CHO cells (31). Taken together, all these data suggest that GO upregulates UCP1 expression through norepinephrine and $\beta$-adrenergic receptor signaling by the activation of both TRPA1 and TRPV1. UCP1 also contributes to energy expenditure and $\mathrm{O}_{2}$ consumption in animal models. Previously, the upregulation of $\mathrm{O}_{2}$ consumption by specific agonist for $\beta 3$-adrenegic receptor was not observed in UCP1-deficient mice $(32,33)$. These data indicate that $\beta 3$-adrenegic stimuli increase energy expenditure via the upregulation of UCP1 protein expression.

In conclusion, the findings of the study demonstrated that GO suppressed body weight gain and WAT mass in the rat model of high fat diet-induced obesity. To the best of our knowledge, in this study, it is demonstrated, for the first time, that GO administration can alter the fuel oxidation rate and increase fat oxidation, leading to a decrease in body weight gain. The anti-obesity effects of GO are due to, at least in part, the upregulation of energy expenditure by UCP1.

\section{Acknowledgements}

Not applicable.

\section{Funding}

This study was supported by grants from Nihon University (to TS) and the programs Grants-in-Aid for Scientific Research (B) (to TS) from the Japan Society for the Promotion of Science (JSPS).

\section{Availability of data and materials}

All data generated or analyzed during the present study are included in this published article.

\section{Authors' contributions}

YK, TH, TS conceived and designed the study. YK conducted the research. YK, YOM, TH, TS analyzed the data and wrote the manuscript. All authors have read and approved the final manuscript.

\section{Ethics approval and consent to participate}

All experiments in this study were performed in accordance with the National Institutes of Health Guide for the Care and Use of Laboratory Animals, and were approved by the Nihon University Animal Care and Use Committee (approval no. AP11B008).

\section{Patient consent for publication}

Not applicable.

\section{Competing interests}

The authors declare that they have no competing interests.

\section{References}

1. Ng M, Fleming T, Robinson M, Thomson B, Graetz N, Margono C, Mullany EC, Biryukov S, Abbafati C, Abera SF, et al: Global, regional, and national prevalence of overweight and obesity in children and adults during 1980-2013: A systematic analysis for the Global Burden of Disease Study 2013. Lancet 384: 766-781, 2014.

2. Rossi F, Punzo F, Umano GR, Argenziano M and Miraglia Del Giudice E: Role of cannabinoids in obesity. Int J Mol Sci 19: E2690, 2018.

3. Golbidi S and Laher I: Exercise induced adipokine changes and the metabolic syndrome. J Diabetes Res 2014: 726861, 2014. 
4. Seki T and Hosono T: Prevention of cardiovascular diseases by garlic-derived sulfur compounds. J Nutr Sci Vitaminol (Tokyo) 61 (Suppl): S83-S85, 2015.

5. García MDC, Pazos P, Lima L and Diéguez C: Regulation of energy expenditure and brown/beige thermogenic activity by interleukins: New roles for old actors. Int J Mol Sci 19: E2569, 2018.

6. Bartelt A and Heeren J: Adipose tissue browning and metabolic health. Nat Rev Endocrinol 10: 24-36, 2014.

7. Ariga $\mathrm{T}$ and Seki T: Antithrombotic and anticancer effects of garlic-derived sulfur compounds: A review. Biofactors 26: 93-103, 2006.

8. Petropoulos S, Fernandes Â, Barros L, Ciric A, Sokovic M and Ferreira ICFR: Antimicrobial and antioxidant properties of various Greek garlic genotypes. Food Chem 245: 7-12, 2018.

9. Fujisawa $H$, Suma K, Origuchi K, Kumagai $H$, Seki $T$ and Ariga T: Biological and chemical stability of garlic-derived allicin. J Agric Food Chem 56: 4229-4235, 2008.

10. Fujisawa H, Suma K, Origuchi K, Seki T and Ariga T: Thermostability of allicin determined by chemical and biological assays. Biosci Biotechnol Biochem 72: 2877-2883, 2008.

11. Fujisawa H, Watanabe K, Suma K, Origuchi K, Matsufuji H, Seki $\mathrm{T}$ and Ariga T: Antibacterial potential of garlic-derived allicin and its cancellation by sulfhydryl compounds. Biosci Biotechnol Biochem 73: 1948-1955, 2009.

12. Ariga T, Tsuj K, Seki T, Moritomo T and Yamamoto JI: Antithrombotic and antineoplastic effects of phyto-organosulfur compounds. Biofactors 13: 251-255, 2000.

13. Seki T, Tsuji K, Hayato Y, Moritomo T and Ariga T: Garlic and onion oils inhibit proliferation and induce differentiation of HL-60 cells. Cancer Lett 160: 29-35, 2000.

14. Hosono T, Fukao T, Ogihara J, Ito Y, Shiba H, Seki T and Ariga T: Diallyl trisulfide suppresses the proliferation and induces apoptosis of human colon cancer cells through oxidative modification of beta-tubulin. J Biol Chem 280: 41487-41493, 2005.

15. Hosono T, Hosono-Fukao T, Inada K, Tanaka R, Yamada H, Iitsuka Y, Seki T, Hasegawa I and Ariga T: Alkenyl group is responsible for the disruption of microtubule network formation in human colon cancer cell line HT-29 cells. Carcinogenesis 29: 1400-1406, 2008.

16. Iitsuka Y, Tanaka Y, Hosono-Fukao T, Hosono T, Seki T and Ariga T: Relationship between lipophilicity and inhibitory activity against cancer cell growth of nine kinds of alk(en)yl trisulfides with different side chains. Oncol Res 18: 575-582, 2010.

17. Hosono-Fukao T, Hosono T, Seki T and Ariga T: Diallyl trisulfide protects rats from carbon tetrachloride-induced liver injury. J Nutr 139: 2252-2256, 2009.

18. Ried K, Frank OR, Stocks NP, Fakler P and Sullivan T: Effect of garlic on blood pressure: A systematic review and meta-analysis BMC Cardiovasc Disord 8: 13, 2008.

19. Ried K, Toben $C$ and Fakler P: Effect of garlic on serum lipids An updated meta-analysis. Nutr Rev 71: 282-299, 2013.

20. Fukao T, Hosono T, Misawa S, Seki T and Ariga T: The effects of allyl sulfides on the induction of phase II detoxification enzymes and liver injury by carbon tetrachloride. Food Chem Toxicol 42 743-749, 2004.
21. Reeves PG: Components of the AIN-93 diets as improvements in the AIN-76A diet. J Nutr 127 (Suppl): 838S-841S, 1997.

22. Lusk G: Analysis of the oxidation of mixtures of carbohydrate and fat: A Correction. J Biol Chem 59: 2, 1924.

23. Bruss MD, Khambatta CF, Ruby MA, Aggarwal I and Hellerstein MK: Calorie restriction increases fatty acid synthesis and whole body fat oxidation rates. Am J Physiol Endocrinol Metab 298: E108-E116, 2010.

24. Shen Y, Fukushima M, Ito Y, Muraki E, Hosono T, Seki T and Ariga T: Verification of the antidiabetic effects of cinnamon (Cinnamomum zeylanicum) using insulin-uncontrolled type 1 diabetic rats and cultured adipocytes. Biosci Biotechnol Biochem 74: 2418-2425, 2010.

25. Lee MS, Kim IH, Kim CT and Kim Y: Reduction of body weight by dietary garlic is associated with an increase in uncoupling protein mRNA expression and activation of AMP-activated protein kinase in diet-induced obese mice. J Nutr 141: 1947-1953, 2011.

26. Joo H, Kim CT, Kim IH and Kim Y: Anti-obesity effects of hot water extract and high hydrostatic pressure extract of garlic in rats fed a high-fat diet. Food Chem Toxicol 55: 100-105, 2013.

27. Kim I, Kim HR, Kim JH and Om AS: Beneficial effects of Allium sativum $\mathrm{L}$. stem extract on lipid metabolism and antioxidant status in obese mice fed a high-fat diet. J Sci Food Agric 93: 2749-2757, 2013.

28. Lii CK, Huang CY, Chen HW, Chow MY, Lin YR, Huang CS and Tsai CW: Diallyl trisulfide suppresses the adipogenesis of 3T3-L1 preadipocytes through ERK activation. Food Chem Toxicol 50: 478-484, 2012.

29. Keophiphath M, Priem F, Jacquemond-Collet I, Clément K and Lacasa D: 1,2-vinyldithiin from garlic inhibits differentiation and inflammation of human preadipocytes. J Nutr 139: 2055-2060, 2009.

30. Yonezawa T, Kurata R, Hosomichi K, Kono A, Kimura M and Inoko $\mathrm{H}$ : Nutritional and hormonal regulation of uncoupling protein 2. IUBMB Life 61: 1123-1131, 2009.

31. Koizumi K, Iwasaki Y, Narukawa M, Iitsuka Y, Fukao T, Seki T, Ariga $\mathrm{T}$ and Watanabe T: Diallyl sulfides in garlic activate both TRPA1 and TRPV1. Biochem Biophys Res Commun 382: $545-548,2009$.

32. Szentirmai É and Kapás L: The role of the brown adipose tissue in $\beta 3$-adrenergic receptor activation-induced sleep, metabolic and feeding responses. Sci Rep 7: 958, 2017.

33. Hankir MK, Kranz M, Keipert S, Weiner J, Andreasen SG, Kern M, Patt M, Klöting N, Heiker JT, Brust P, et al: Dissociation between brown adipose tissue 18F-FDG uptake and thermogenesis in uncoupling protein 1-deficient mice. J Nucl Med 58: $1100-1103,2017$

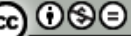

This work is licensed under a Creative Commons Attribution-NonCommercial-NoDerivatives 4.0 International (CC BY-NC-ND 4.0) License. 